\title{
Dermal Ultrastructure in Low Beighton Score Members of 17 Families with Hypermobile-Type Ehlers-Danlos Syndrome
}

\author{
Trinh Hermanns-Lê,, ${ }^{1}$ Marie-Annick Reginster, ${ }^{1}$ Claudine Piérard-Franchimont, ${ }^{1}$ \\ Philippe Delvenne, ${ }^{1}$ Gérald E. Piérard, ${ }^{1}$ and Daniel Manicourt ${ }^{2}$
}

${ }^{1}$ Department of Dermatopathology, University Hospital Sart Tilman, 4000 Liège, Belgium
${ }^{2}$ Department of Rheumatology, Saint-Luc University Hospital, 1200 Brussels, Belgium

Correspondence should be addressed to Gérald E. Piérard, gerald.pierard@ulg.ac.be

Received 13 March 2012; Accepted 12 July 2012

Academic Editor: Richard Tucker

Copyright ( 2012 Trinh Hermanns-Lê et al. This is an open access article distributed under the Creative Commons Attribution License, which permits unrestricted use, distribution, and reproduction in any medium, provided the original work is properly cited.

\begin{abstract}
The distinction between the Ehlers-Danlos syndrome hypermobile type (EDSH) and the benign joint hypermobility syndrome (BJHS) is unclear. The aim of the present study was to compare skin ultrastructural abnormalities of EDSH and BJHS among different families. Skin of 23 EDSH, 27 BJHS, and 41 asymptomatic subjects from 17 families was examined using transmission electron microscopy. Similar ultrastructural abnormalities were found irrespective of the Beighton score. Flower-like collagen fibrils represented the key change and elastic fibers were altered as well. Beighton score is a clinical parameter rating joint mobility that appeared unrelated to quantitative and qualitative collagen ultrastructural alterations in the skin. Some EDSH family members fit with BJHS diagnosis. BJHS possibly represents a mild variant of EDSH.
\end{abstract}

\section{Introduction}

Ehlers-Danlos syndrome (EDS) is a cluster of inherited connective tissue disorders, mainly characterized by skin hyperextensibility, joint hyperlaxity, and tissue fragility. Both the classical and hypermobile (EDSH) EDS types are recognized as the most frequent presentations [1]. The prevalence of EDSH is estimated to range from $1 / 5,000$ to $1 / 20,000$. The major diagnostic criteria for EDSH are joint hypermobility associated with skin hyperextensibility and/or velvety aspect [2]. Recurrent joint dislocations, chronic joint/limb pain, and positive family history are considered as minor diagnostic criteria. Of note, joint laxity is common in healthy children under 5 years of age and appears to be related to gender and race [3-5]. Women usually show more extensive joint laxity than men. African, Asian, and Middle Eastern people present a similar physiological feature $[6,7]$.

Abnormal joint mobility is conveniently assessed using the Beighton scale. A score reaching 5/9 or above defines EDSH. Type III collagen [8] and tenascin-X [9] were reported to be mutated, but molecular abnormalities remain often undisclosed. By contrast, dermal ultrastructural features are commonly indicative [10-12].

Joint laxity is further present in the benign joint hypermobile syndrome (BJHS) [5] identified using the Brighton criteria [13]. The Beighton score must reach at least 4, and arthralgia be present in 4 or more joints for more than 3 months. Minor criteria combine a lower Beighton score and subluxation in more than one joint or in a single joint on more than one occasion as well as skin hyperextensibility and abnormal scarring. According to these definitions, the diagnostic criteria of EDSH and BJHS overlap. Accordingly, EDSH and BJHS are considered to be the same disorder by some authors [11, 14-17].

The aim of the present work was to revisit ultrastructural features in the skin of EDSH patients and their family members showing a lower Beighton score and/or with BJHS criteria.

\section{Methods}

A total of 91 consecutive patients, aged 9-62 years, from 17 families were explored using transmission electron 
TABLE 1: Frequency of finding flower-like collagen fibrils (FCF) in patients with Ehlers-Danlos syndrome hypermobile (EDSH) and in patients with the benign joint hypermobility syndrome (BJHS).

\begin{tabular}{lcc}
\hline Disease status & Number of patients & Number of cases with FCF \\
\hline EDSH & 23 & 23 \\
BJHS & 27 & 27 \\
Unaffected & 41 & 15 \\
\hline
\end{tabular}

microscopy. They were referred to rheumatology departments for familial joint hyperextensibility. Clinical assessments and skin biopsies were performed with the consent of the patients or the parents of minors. A total of 23 patients (20 women and 3 men) from the 17 families had a provisional diagnosis of EDSH according to the Villefranche nosology [1], and 68 other members of these 17 families presented with a Beighton score $4 / 9$ or lower. A total of 27/68 subjects (18 men and 9 women) suffered from BJHS as defined by the Brighton criteria.

Skin samples were prepared for transmission electron microscopy. They were immersed in $4 \%$ glutaraldehyde in a phosphate buffer at $\mathrm{pH} 7.4$, postfixed in $1 \%$ osmium tetroxide, and embedded in epon. The ultrathin sections were double-stained with uranyl acetate and lead citrate. Observations were made under a Zeiss EM910 electron microscope operated at $60 \mathrm{kV}$. The diagnostic criteria were previously discussed $[10,12]$.

\section{Results}

The study started April 2008 until September 2011. The majority $65 / 91$ of the skin samples (Table 1) showed flowerlike collagen fibrils (FCF) in the papillary and/or reticular dermis (Figure 1). FCF were observed in all patients with EDSH and BJHS diagnosis, and in 15 apparently asymptomatic subjects as well. No gender influence was disclosed in the ultrastructural changes. The FCF numbers varied and appeared unrelated to the Beighton score. Other abnormalities of the connective tissue extracellular matrix (ECM) consisted of variable collagen fibril diameters, twisted collagen fibrils, irregular interfibrillar spacing, and granulofilamentous deposits inside the collagen bundles as well as whirled or disorganized bundles. The elastic fiber changes consisted of frayed contours, increased osmiophilic structures even in young subjects, and inclusions of calcified (Figure 2) or uncalcified microcavities. Large stellate globules of superposed hyaluronic acid (Figure 3 ) and focal granulofilamentous deposits were disclosed in the interstitial ECM.

Intrafamilial dermal changes generally looked similar. In a 3/17 families, dermal changes were found in both parents. A total of 26 asymptomatic subjects of these families exhibited normal ultrastructural dermal features.

\section{Discussion}

Subjects with a Beighton score lower than 5/9 were not clinically considered as EDS. However, they showed dermal

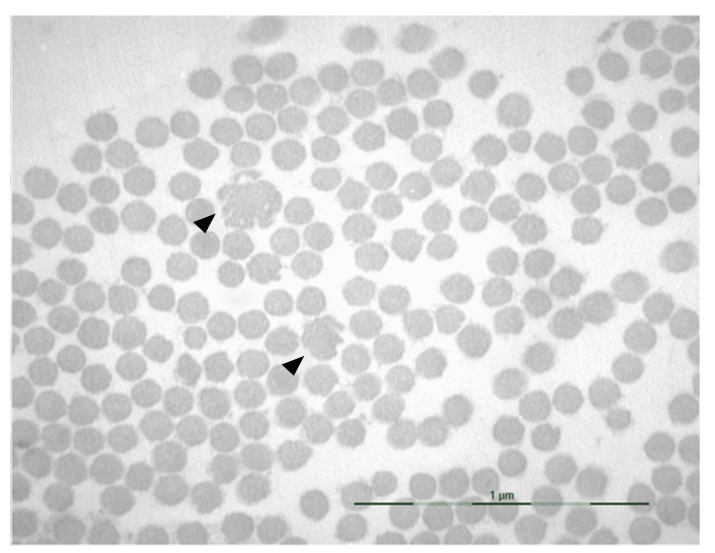

Figure 1: Flower-like collagen fibrils $(\bullet)$ and irregular interfibrillar spaces.

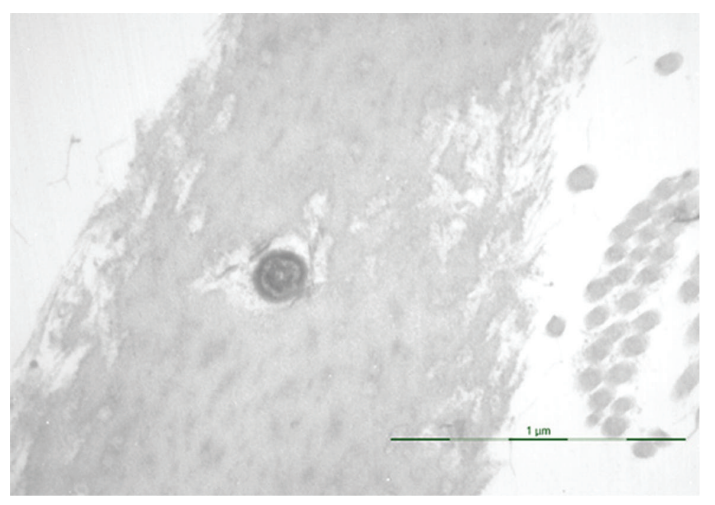

Figure 2: Calcified microcyst in an elastic fiber.

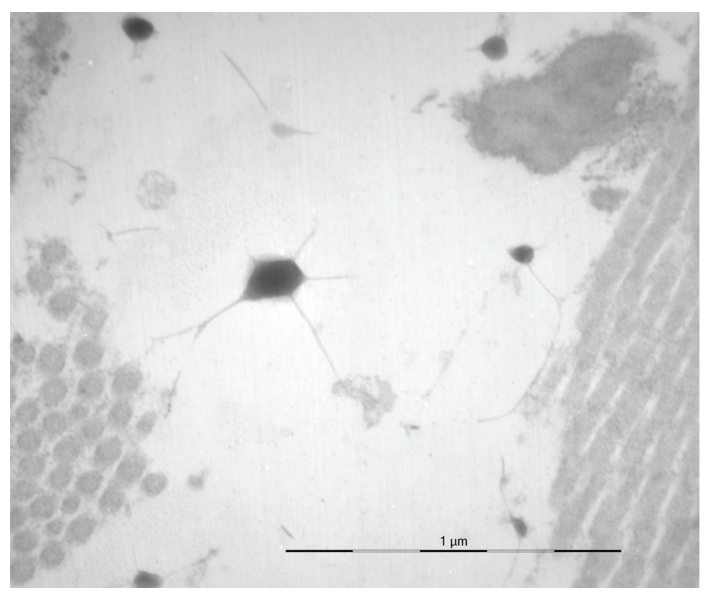

FIgURE 3: Globules of presumably hyaluronic acid and granulofilamentous meshwork inside the collagen bundles.

abnormalities including FCF as described earlier [10-12, 18]. In addition, ultrastructural ECM abnormalities were presently found in asymptomatic or low Beighton score subjects of EDS family pedigrees. These subjects possibly presented a subclinical EDS, or their joint hyperlaxity had possibly vanished with ageing and/or arthrosis. The 
presence of the dermal abnormalities was consistent with the genetic transmission of EDS morphological features from asymptomatic parents to their children. According to the Brighton criteria, 27 of the EDS family members fitted with BJHS diagnosis, and their dermal ECM showed typical EDS ultrastructural abnormalities. Accordingly, we support the concept that BJHS represents a mild variant of EDSH [1417].

In spite of the relatively unspecific ultrastructural criteria of EDS, the global architecture and the ultrastructure of the dermal ECM are of diagnostic relevance, and they occasionally suggest a specific EDS type. For instance, abundant granulofilamentous deposits are found in subjects with mutations in the gene coding for tenascin-X. For these reasons, ultrastructural examination of the dermis is potentially helpful for confirming the diagnosis of EDS, and for disclosing some family members carrying the ECM alterations. The defects in collagen fibril formation are likely multiple suggesting variable penetrance.

\section{Acknowledgments}

This work was supported by a grant from the "Fonds d'Investissement de la Recherche Scientifique" of the University Hospital of Liège. No other sources of funding were used to assist in the preparation of this paper. The authors have no conflict of interest that are directly relevant to the content of this paper. The authors appreciate the excellent secretarial assistance of Mrs. Ida Leclercq and Marie Pugliese.

\section{References}

[1] P. Beighton, A. de Paepe, B. Steinmann, P. Tsipouras, and R. J. Wenstrup, "Ehlers-Danlos syndrome: revised nosology, Villefranche, 1997," American Journal of Medical Genetics, vol. 77, no. 1, pp. 31-37.

[2] F. Henry, V. Goffin, C. Piérard-Franchimont, and G. E. Piérard, "Mechanical properties of skin in Ehlers-Danlos syndrome, types I, II, and III," Pediatric Dermatology, vol. 13, no. 6, pp. 464-467, 1996.

[3] U. Seçkin, B. S. Tur, O. Yilmaz, I. Yağci, H. Bodur, and T. Arasil, "The prevalence of joint hypermobility among high school students," Rheumatology International, vol. 25, no. 4, pp. 260 263, 2005.

[4] D. B. Everman and N. H. Robin, "Hypermobility syndrome," Pediatrics in Review, vol. 19, no. 4, pp. 111-117, 1998.

[5] M. R. Simpson, "Benign joint hypermobility syndrome: evaluation, diagnosis, and management," Journal of the American Osteopathic Association, vol. 106, no. 9, pp. 531-536, 2006.

[6] Z. S. Al-Rawi, A. J. Al-Aszawi, and T. Al-Chalabi, "Joint mobility among university students in Iraq," British Journal of Rheumatology, vol. 24, no. 4, pp. 326-331, 1985.

[7] F. N. Birrell, A. O. Adebajo, B. L. Hazleman, and A. J. Silman, "High prevalence of joint laxity in West Africans," British Journal of Rheumatology, vol. 33, no. 1, pp. 56-59, 1994.

[8] P. Narcisi, A. J. Richards, S. D. Ferguson, and F. M. Pope, "A family with Ehlers-Danlos syndrome type III/articular hypermobility syndrome has a glycine 637 to serine substitution in type III collagen," Human Molecular Genetics, vol. 3, no. 9, pp. 1617-1620, 1994.
[9] M. C. Zweers, W. B. Dean, T. H. van Kuppevelt, J. Bristow, and J. Schalkwijk, "Elastic fiber abnormalities in hypermobility type Ehlers-Danlos syndrome patients with tenascin-X mutations," Clinical Genetics, vol. 67, no. 4, pp. 330-334, 2005.

[10] I. Hausser and I. Anton-Lamprecht, "Differential ultrastructural aberrations of collagen fibrils in Ehlers-Danlos syndrome types I-IV as a means of diagnostics and classification," Human Genetics, vol. 93, no. 4, pp. 394-407, 1994.

[11] T. Kobayasi, "Abnormality of dermal collagen fibrils in Ehlers Danlos syndrome. Anticipation of the abnormality for the inherited hypermobile disorders," European Journal of Dermatology, vol. 14, no. 4, pp. 221-229, 2004.

[12] T. Hermanns-Lê and G. E. Piérard, "Ultrastructural alterations of elastic fibers and other dermal components in EhlersDanlos syndrome of the hypermobile type," American Journal of Dermatopathology, vol. 29, no. 4, pp. 370-373, 2007.

[13] R. Grahame, H. A. Bird, and A. Child, "The revised (Brighton 1998) criteria for the diagnosis of benign joint hypermobility syndrome (BJHS)," Journal of Rheumatology, vol. 27, no. 7, pp. 1777-1779, 2000.

[14] R. Grahame, "Joint hypermobility and genetic collagen disorders: are they related?" Archives of Disease in Childhood, vol. 80, no. 2, pp. 188-191, 1999.

[15] R. Grahame, "Heritable disorders of connective tissue," Bailliere's Best Practice and Research in Clinical Rheumatology, vol. 14, no. 2, pp. 345-361, 2000.

[16] N. Adib, K. Davies, R. Grahame, P. Woo, and K. J. Murray, "Joint hypermobility syndrome in childhood. A not so benign multisystem disorder?” Rheumatology, vol. 44, no. 6, pp. 744750, 2005.

[17] M. C. Zweers, M. Kucharekova, and J. Schalkwijk, “Tenascin$\mathrm{X}$ : a candidate gene for benign joint hypermobility syndrome and hypermobility type Ehlers-Danlos syndrome?" Annals of the Rheumatic Diseases, vol. 64, no. 3, pp. 504-505, 2005.

[18] T. Hermanns-Lê and G. E. Piérard, "Collagen fibril arabesques in connective tissue disorders," American Journal of Clinical Dermatology, vol. 7, no. 5, pp. 323-326, 2006. 


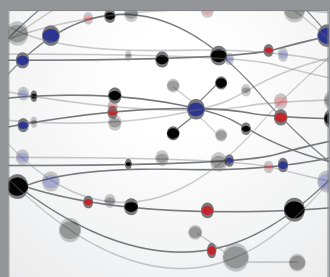

The Scientific World Journal
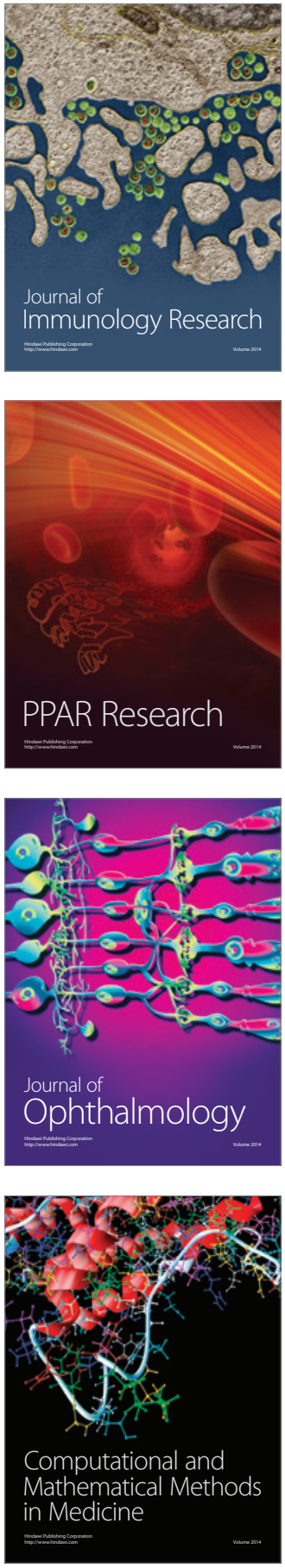

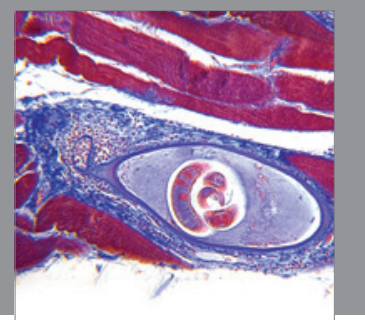

Gastroenterology

Research and Practice
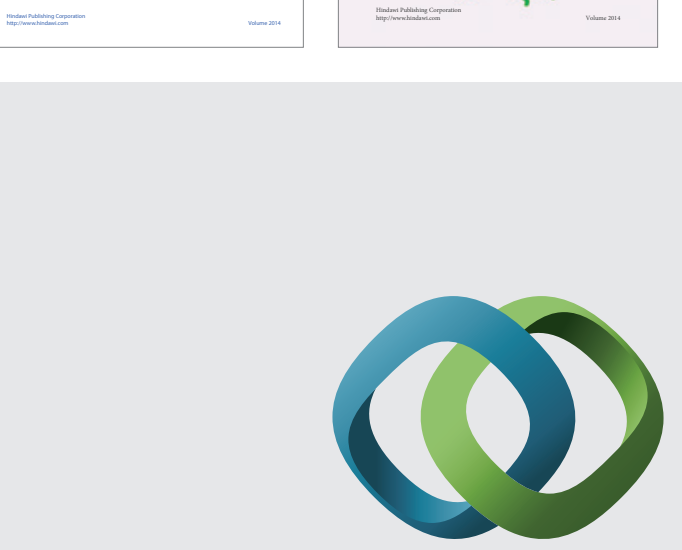

\section{Hindawi}

Submit your manuscripts at

http://www.hindawi.com
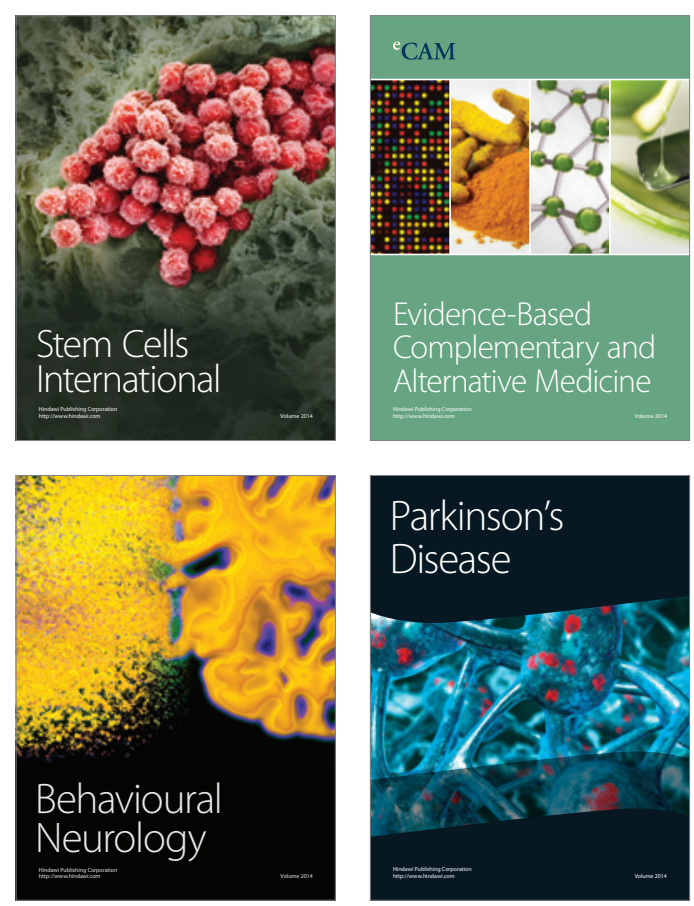

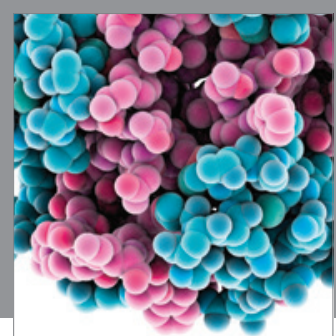

Journal of
Diabetes Research

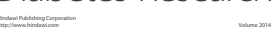

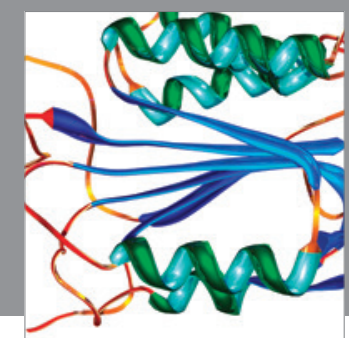

Disease Markers
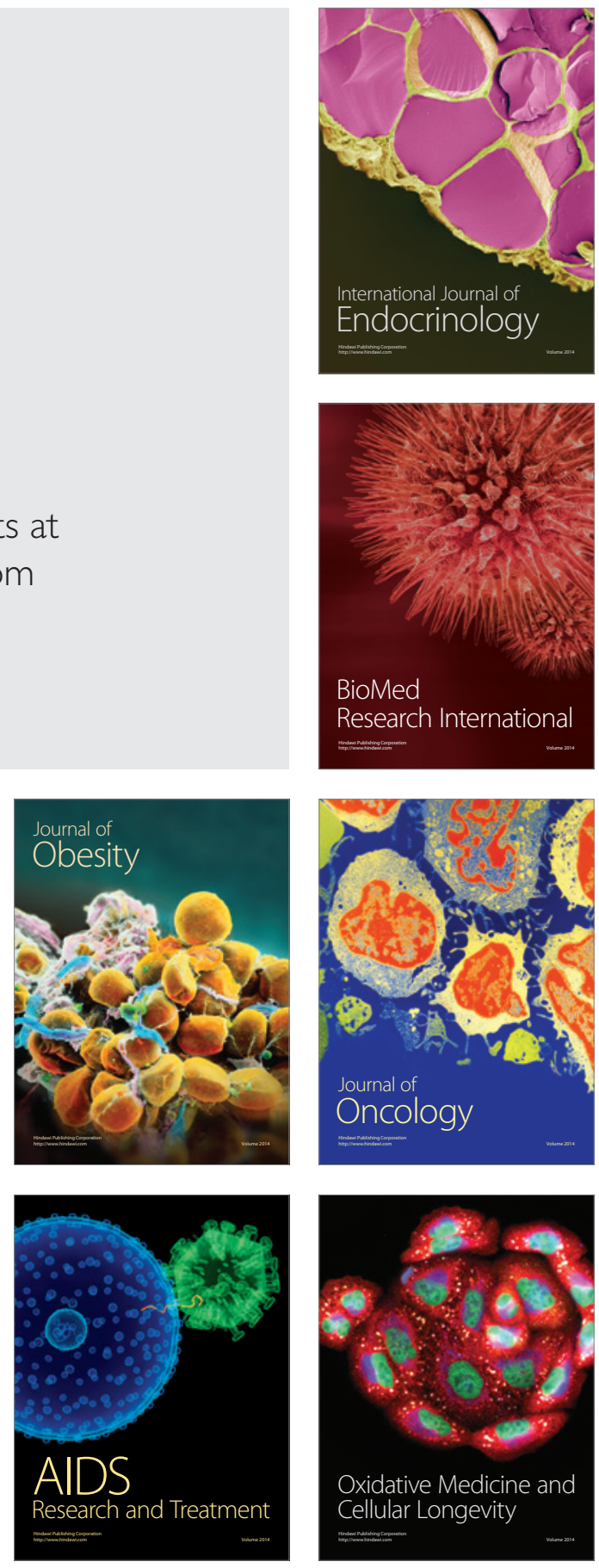